\title{
Investigations on Thermal Insulation and Vapor Resistance of Body Armor Using Thermal Manikin Method
}

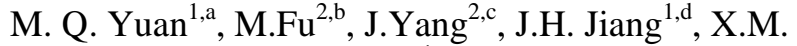 \\ Qian $^{1, \mathrm{e}}$ \\ ${ }^{1}$ School of Mechatronical Engineering, Beijing Institute of \\ Technology, Beijing, 100081, China
}

\begin{abstract}
With the frequent occurrences of the violence incidents, research on body armor is paid much attention to. To study the human physiological responses when wearing body armor and to improve the wearing comfort of body armor, a thermal manikin was used to measure the thermal insulation and vapor resistance of two types of body armor (stab-resistance and bulletproof, respectively) in a climate chamber. Results show the coverage levels on body part and material selections on protection layer affect the thermal insulation and vapor resistance of the body armors. Moreover, air temperature and relative humidity of the climate chamber have an influence on the moisture transfer of the body armors. The findings in this study could establish a data support for body armor, with thermophysical property improvement and design optimization.
\end{abstract}

Keywords-stab-resistance; bulletproof; body armor; thermal manikin; thermal insulation; vapor resistance

\section{INTRODUCTION}

The US National Institute of Justice established NIJ 115 'Stab resistance Standard for Body Armor', in which stated that the body armor design principle should be 'wearability + adequate protection=life saving' [1], which means the implication of the body armor should prevent the case of putting human into the dangerous situation due to the rare wearing frequency of body armor. In this case, the 'wearablity' significantly influences the wearing frequency of body armor, which is the standing point of this research.

It is normally required that the human core temperature maintaining at $37^{\circ} \mathrm{C}$ to ensure physiological comfort [2]. The body armor is an important media for heat exchange between human and the environment. As special personal protective clothing, the heat and moist transfer properties of body armor are unique. Multi-layered protection material leads to heat stress, which results in human psychological exhaustion and fatigue [3]. Thus, it is important to study the heat and moisture transfer within the human-body armor-environment, to prevent the fatigue danger caused by heat strain and poor protection due to the low wearbility [4].

Subjective and objective methods are the two domain evaluation methods to study the heat and moisture transfer of protective clothing[5]. Subjective method suffers from the fortuity, since each person responses differently on the same question. Objective method includes the thermal manikin experiment. Thermal insulation is the thermal energy reduction between two sides of the clothing per unit

\author{
${ }^{2}$ Institute of Public Safety Research, Department of \\ Engineering Physics, Tsinghua University, Beijing, \\ 100084, China \\ amyuan@bit.edu.cn,'fm10@mails.tsinghua.edu.cn, ${ }^{\mathrm{c}}$ yangji \\ esxu@163.com, ${ }^{\mathrm{d}}$ bit809007@sina.com, \\ eqsemon@bit.edu.cn
}

area. The vapor resistance implies the water vapor pressure difference between two sides of the clothing per unit area [6].

Research on thermal manikin has been conducted for 70 years. It is one of the most used methods to measure the thermal insulation and vapor resistance under the normal condition [5]. Wang [7] et al. used the thermal manikin 'Walter' to measure the heat and moist transfer on three groups of clothes, to analyze the geological area effect. Li [8] et al. used the manikin 'Walter' to investigate the thermophysical properties of high thermal-insulated clothes in cold environments. Han [9] et al. developed a disaster simulation system by using the thermal manikin 'Newton', and simulated the human physiological characteristics in cold environments. In this research, the thermal manikin 'Newton' was used to measure the thermal insulation and vapor resistance of two types of body armor. The physiological properties of those types of body armor were analyzed.

\section{METHODOLOGY}

\section{A. Experimental Device and Materials}

The 20-zone sweating thermal manikin 'Newton' (Measurement Technology Northwest. Inc, USA) was used to measure the thermal insulation and vapor resistance of body armors. It has an averaged Asian adult size, with each zone individually controls the temperature, heat flux and sweating rate from the software ThermDAC [10]. It is constructed of a thermally conductive aluminum filled carbon-epoxy shell with embedded heating and sensor wire elements [11]. The manikin can be used in constant temperature mode or constant heat flux mode. The temperatures of each zones are measured by an array of temperature coefficient resistance wire sensors, with precision of $\pm 0.1^{\circ} \mathrm{C}$. The manikin system equips with a circulation pump to distribute water into 20 zones. Water from the container is automatically and continuously purged into the manikin pores, and the volumetric flow rate for each zone is adjustable in the control software ThermDAC.

Experiments were conducted in a climate chamber, in which the temperature and humidity could independently controlled at range of $18-48{ }^{\circ} \mathrm{C}\left( \pm 0.5^{\circ} \mathrm{C}\right)$ and $30-80 \%( \pm$ $5 \%$ ), respectively [12]. The size of the chamber is $6 \mathrm{~m} \times 5$ $\mathrm{m} \times 2.7 \mathrm{~m}$ (length $\times$ width $\times$ height). The wall of the chamber is made of polystyrene foam composite panel and steel plates, to ensure the integral enclosure and structural 
support. Air flowed from the ceiling to the floor to keep a constant temperature and humidity of the chamber. Ten WZP-PT100 thermocouples $\left( \pm 0.1^{\circ} \mathrm{C}\right)$ were distributed in the chamber to detect the air temperatures [13], and an AM-101 humidity sensor ( $\pm 3 \%$ ) was placed in the center of the climate chamber, to measure the humidity [14].

Two types of body armor were used. One is a stab-resistance body armor (named as BA1), meeting the China GA-2008 Standard [15]. Its protection layer is made of alloy steel plates. Another one is a bulletproof body armor (named as BA2), meeting the China GA141-2010 Standard [16]. Its protection layer is made of ultra high molecular modulus weight polyethylene (UMWPE) and aramid. Both body armors are vest style, consist of outer shell, inner conform layer, and protection layer. The protection area is $0.3 \mathrm{~m}^{2}$, as the standards required.

\section{EXPERIMENTAL DESIGN AND CALCULATION METHOD}

\section{A. Thermal Insulation Experiment}

Experiments were conducted in the climate chamber with air temperatures of $20^{\circ} \mathrm{C}$ and $30^{\circ} \mathrm{C}$, and relative humidity (RH) of 55\%. According to ISO 9920 and ASTM F1291, the experiments were firstly performed with the manikin wearing well-fitted $0.1 \mathrm{~mm}$ thick knit cotton fabric. The experiments were then performed with the manikin wearing body armor. The constant skin temperature $\left(35^{\circ} \mathrm{C}\right)$ was applied without sweating, to measure the thermal insulation. Each experiment lasted for 1 hour. The software ThermDAC recorded the heat fluxes and temperatures of four focused zones: chest, stomach, shoulder, and back. Each measurement was repeated three times, the average value and standard deviation were obtained. Serial and parallel calculation methods were used to acquire the total thermal insulation. The thermal insulation of each zone is obtained:

$$
R_{c t, i}=\frac{T_{s k i n, i}-T_{a m b}}{Q_{i}} .
$$

Where $R_{c t, i}$ is the localized heat insulation, $\mathrm{m}^{2} \mathrm{~K} / \mathrm{W}$; $T_{\text {skin, } i}$ is the localized skin temperature, $\mathrm{K} ; T_{a m b}$ is the air temperature of the climate chamber, $\mathrm{K} ; Q_{i}$ is the localized heat flux, $\mathrm{W} / \mathrm{m}^{2}$.

The total thermal insulations are calculated by serial and parallel calculation methods:

$$
\begin{aligned}
& R_{\text {serial }}=\sum_{1}^{N}\left(R_{c t, i} \times a_{i}\right) . \\
& R_{\text {parallel }}=1 / \sum_{1}^{N} \frac{a_{i}}{R_{c t, i}} .
\end{aligned}
$$

Where $R_{\text {serial }}$ and $R_{\text {parallel }}$ are the total thermal insulation calculated by serial and parallel calculation method, respectively. $\mathrm{N}$ is the total number of the measured zones of the manikin. $a_{i}$ is the local zone surface area ratio.

\section{B. Vapor Resistance Experiment}

The experiments were conducted with air temperatures of $20^{\circ} \mathrm{C}$ and $30^{\circ} \mathrm{C}$, and $\mathrm{RH}$ of $40 \%, 55 \%$ and $70 \%$. According to ASTM 2370, measurements were conducted with the manikin wearing cotton fabric and body armor. The constant sweating mode was selected, with the sweating rate of $200-300 \mathrm{~mL} /\left(\mathrm{hm}^{2}\right)$. The ThermDAC output was selected and processed. The vapor resistance was calculated as:

$$
R_{e t, i}=\frac{\left|P_{s a t}-P_{a m b}\right|}{Q_{i}-\left[\left(T_{s k i n}-T_{a m b}\right) / R_{c t, i}\right]} .
$$

Where $R_{e t, i}$ is the localized vapor resistance, $\mathrm{kPa} . \mathrm{m}^{2} / \mathrm{W} . P_{\text {sat }}$ and $P_{a m b}$ are saturated vapor pressures of the climate chamber and the skin surface of the thermal manikin, respectively, $\mathrm{kPa}$ :

$$
\begin{aligned}
& P_{\text {sat }}=0.133 \times 10^{\left[8.10765-\left(1750.29 /\left(235+T_{\text {ssin }}\right)\right)\right]} . \\
& P_{a m b}=R H \times 0.133 \times 10^{\left[8.10765-\left(1750.29 /\left(235+T_{\text {anb }}\right)\right)\right]}
\end{aligned}
$$

\section{RESULTS AND DISCUSSION}

\section{A. Thermal Insulation}

Fig. 1(a) shows the comparison of the total thermal insulation under different conditions. Results obtained from the serial calculation method are larger than those from the parallel calculation method, which is consistent with the results reported [4]. The total thermal insulation reaches $0.23-0.3 \mathrm{~m}^{2} \mathrm{~K} / \mathrm{W}$ in $20^{\circ} \mathrm{C}$, and varies to $0.2-0.25$ $\mathrm{m}^{2} \mathrm{~K} / \mathrm{W}$ in $30{ }^{\circ} \mathrm{C}$. For the sample BA1, total thermal insulation increases with the air temperature increasing, since the thermal conductivity of alloy steel increases significantly with the air temperature. For the sample BA2, the total thermal insulation decreases with the air temperature increasing. A possible illustration would be the temperature does not influence obviously on the polymers comparing to alloy steel. In addition, the setup temperature $\left(30^{\circ} \mathrm{C}\right)$ is close to the skin surface temperature of the manikin $\left(35^{\circ} \mathrm{C}\right)$, so the heat flux was limited and unstable.

Fig. 1(b) shows the comparison of the localized thermal insulation under different temperatures. It is noticed that the thermal insulation is higher on the stomach and back zones, while lower on the chest and shoulder zones. This phenomenon could be associated with the design feature of 
the body armor vest. The stomach and back zones are well covered, thus less heat is conducted through the clothing layers. However, the chest and shoulder zones are half covered. Heat could easily transfer form the boundaries to the air.

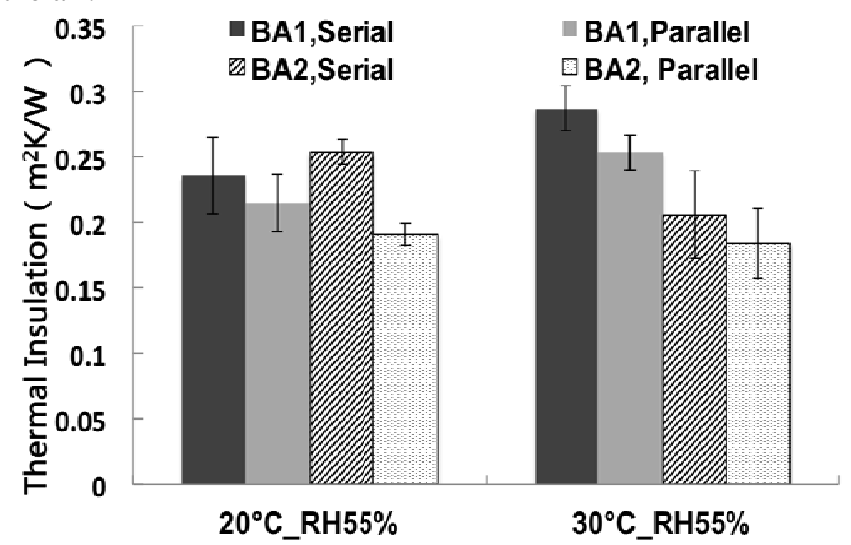

(a) Total thermal insulation

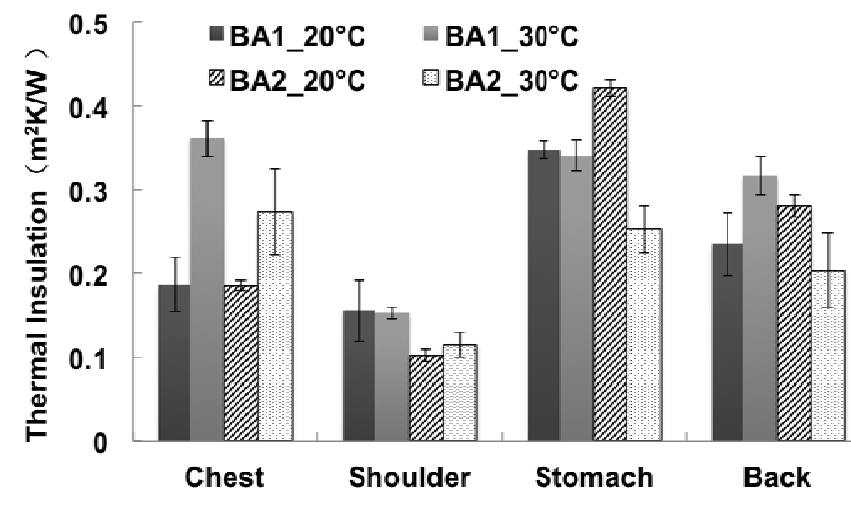

(b) Localized thermal insulation

Figure 1. Comparison of the thermal insulation of body armors under different environment conditions.

\section{VAPOR RESISTANCE}

Fig.2(a) shows the comparison of total vapor resistance under different environment conditions. It can be seen that the results obtained from serial calculation method are larger than those from parallel calculation method. In addition, when $\mathrm{RH}$ remains at 55\%, the total vapor resistance increases with the air temperature increasing, which could be explained by the difference of water vapor pressure and the difference of manikin heat flux. The relative humidity is the ratio of the partial pressure of water vapor to the equilibrium vapor pressure of water at the same temperature. So when air temperature of climate chamber increasing, the equilibrium vapor pressure will increase when $\mathrm{RH}$ remains constant. Thus, the partial water vapor pressure is increasing, leading to lower sweating evaporative rate and less heat flux from the manikin.

It can be also shown that under the same chamber air temperature, the total vapor resistance decreases with $\mathrm{RH}$ increasing, for that the sweat evaporative rate is slower that when the test environment is more saturated. Furthermore, the sample BA1 has higher total evaporative than that of the sample BA2. It can be attributed to the design and fabricate characters of the protection layer. The protection layer for the sample BA2 is made from UMWPE with aramid, with which the interspace is wider than the molded alloy steel, leading to higher speed of sweat evaporation.

Fig. 2(b) shows the comparison of the localized vapor resistance under different conditions. It exhibits that the localized vapor resistances in the stomach and back zones are larger than those in the chest and shoulder zones. The sweating rate is lower, since the manikin stomach and back zones are more covered. Higher vapor resistance indicates less sweat evaporation, so that the possibility of the physiology fatigue is raised.

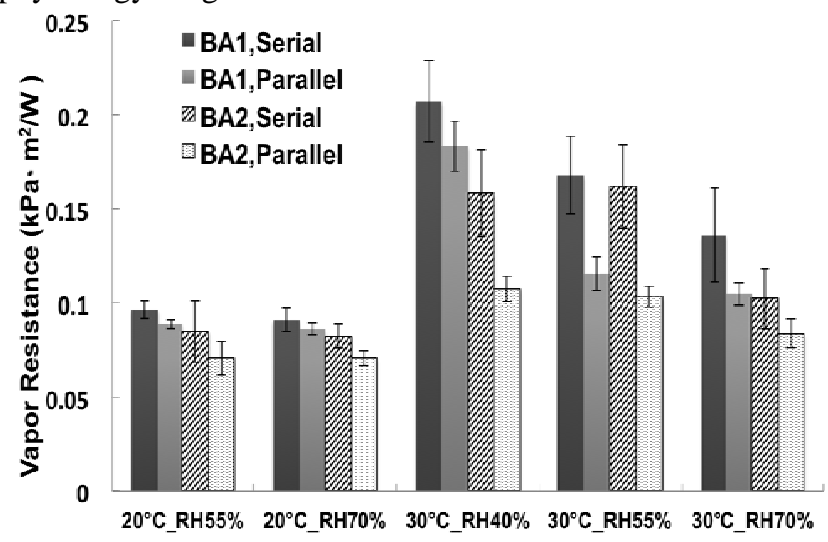

(a) Total vapor resistance

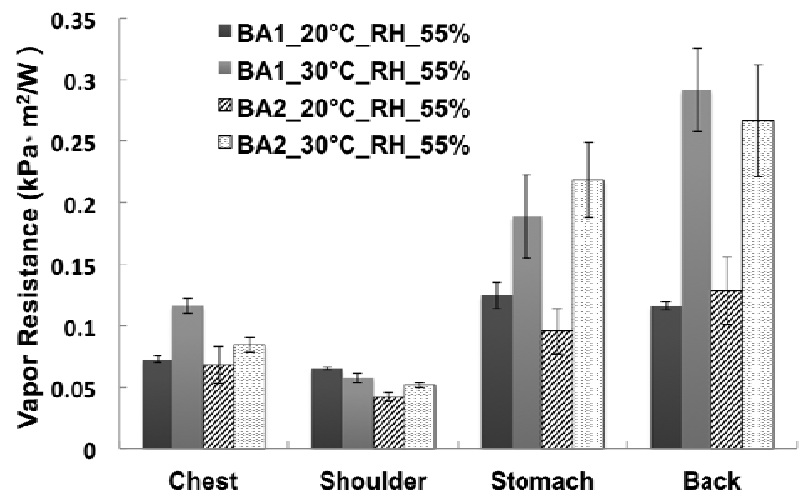

(b) Localized vapor resistance

Figure 2. Comparison of the vapor resistance of body armors under different environment conditions.

\section{SUMMARY}

Experiments on thermal insulation and vapor resistance of two body armors were conducted in a temperature and humidity individually controlled climate chamber. Effects of air temperature, relative humidity of the climate chamber, and material of the protection layer were studied. Results show the total thermal insulation is between $0.2-0.3 \mathrm{~m}^{2} \mathrm{~K} / \mathrm{W}$ in room temperatures, and the localized 
thermal insulations are higher in the stomach and back zones. The total vapor resistance is between 0.1-0.25 $\mathrm{Kpa} \cdot \mathrm{m}^{2} \mathrm{~K} / \mathrm{W}$ in room temperatures, increases with the temperature increasing, and decreases with the relative humidity increasing. The localized vapor resistances are higher in the stomach and back zones. The vapor resistance of stab-resistance body armor is higher than that of bulletproof body armor, which indicates the higher possibly of physiology fatigue. The findings in this study could establish a data support for body armor thermophysical property improvement and design optimization.

\section{REFERENCES}

[1] NIJ115. Nat. Ins. Just. (2000)

[2] P., Kuklane, Candas V: Int. J. Oc. Safe. Erg. Vol. 16 (2010), p. 231.
[3] G. Havenith, I. Holmer, K. Parsons : Ener. Build. Vol. 34 (2002), p. 581.

[4] M. Fu, W.G. Weng, X. F.Han: J. Tsing. Un. (2012), published online. [5] Y. Q. Zhang: Text. Eng., (2012).

[6] Y. Liu, X.Q. Dai: Ch. Pers. Prot. Equip. Vol. 1(2014), p. 32.

[7] F. M.Wang, F. Hu, X. H. Zhou, J. T. Fan, S. Y. Wang: Adv. Text. Tech. Vol. 16 (2007).

[8] F.F. Li: Text. Eng., 2014.

[9] X. F. Han, W. G. Weng, M. Fu: Res. Exp. Lab., Vol. 7(2012) , p. 84. [10] Y. Jie, W.G. Weng, M. Fu: 2014 Int. Sym. Safe. Sci. Tech., (043).

[11] F.M. Wang: 7th Int. Therm. Man. Mod. (2008).

[12] J. Yang, W.G., Weng, B.T. Zhang: J. Therm. Bio. Vol 45 (2014), p. 54.

[13] Proj. Spec. Therm. RTD, (2013).

[14] H. Env. Meas. PMV-PPD , (2013)

[15] GA68-2008, Ch. Min. Pub. Sec. (2008).

[ 1 6] GA141-2010, Ch. Min. Pub. Sec. (2010) 